\begin{tabular}{|c|c|c|}
\hline $\begin{array}{l}\text { PKS } \\
\text { PUBLC } \\
\text { KNOWLDGE } \\
\text { PROJECT }\end{array}$ & $\begin{array}{c}\text { REVISTA DE GEOGRAFIA } \\
\text { (RECIFE) } \\
\text { http://www.revista.ufpe.br/revistageografia }\end{array}$ & 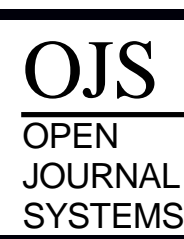 \\
\hline
\end{tabular}

\title{
DIFERENCIAÇÕES URBANO-REGIONAIS NA AMAZÔNIA BRASILEIRA: A ESTRUTURA METROPOLITANA DE SÃO LUÍS E O PERFIL DA METROPOLIZAÇÃO DA AMAZÔNIA ORIENTAL
}

\author{
Tiago Veloso Santos ${ }^{1}$ \\ ${ }^{1}$ Professor do Instituto Federal de Educação,Ciência e Tecnologia do Pará.Email: tiago.veloso@ifpa.edu.br
}

Artigo recebido em 25/05/2016 e aceito em 19/10/2017

\begin{abstract}
RESUMO
O presente artigo tem como objetivo analisar a diversidade urbana e regional na Amazônia brasileira, tomando como parâmetro a relação entre metrópole e região. A partir de aspectos da formação histórica e territorial regional e da existência de uma fronteira econômica que se expande de forma desigual e diferenciada no interior da região, se reconhece a formação de distintas sub-regiões, e, como expressão metropolitana em particular, adota-se como referência empírica, a metrópole de São Luís, capital do Maranhão, produto, condição e meio de um processo de metropolização na porção Oriental da Amazônia. Assim, tomando como parâmetro a relação que a metrópole estabelece com a região, busca-se mostrar a importância e o significado dessa metrópole em face de processos diferenciados de produção do espaço regional, bem como a estrutura intraurbana que apresenta atualmente.
\end{abstract}

Palavras-chave: Amazônia. Metropolização. Região Metropolitana. São Luís.

\section{URBAN-REGIONAL DIFFERENTIATIONS IN THE BRAZILIAN AMAZON: THE METROPOLITAN STRUCTURE OF SÃO LUÍS AND THE PROFILE OF THE METROPOLIZATION OF THE EASTERN AMAZON}

\begin{abstract}
The present paper has the aim to analyze the urban and regional diversity in the Brazilian Amazon, using, as a parameter, the relationship between metropolis and region. From historical and regional territorial formation and the existence of an economics frontier that expands in an unequal shape and differentiated within the region, it is recognized the formation of distinct sub-regions, and as a peculiar metropolitan expression, it is adopted as an empirical reference, São Luis metropolis, capital of the State of Maranhão, product, condition and ambient of a process of metropolization in the Eastern part of the Amazon. Thus, taking the relationship that the metropolis establishes with the region as a parameter, it is aimed to show the importance and the significance of such metropolis as for the several processes of production in the regional space, as well as with the intra-urban structure that it presents nowadays.
\end{abstract}

Key-words: Amazon. Metropolization. Metropolitan Region. São Luís. 


\section{INTRODUÇÃO}

Nas últimas três décadas, uma tendência crescente de urbanização vem se intensificando na Amazônia. A imagem da floresta urbanizada projetada por Becker (1990) é simbólica nesse sentido. Acompanhando as tendências de urbanização do território brasileiro, a região já apresentava cerca de $70 \%$ de sua população vivendo em áreas urbanas no início do século XXI, em contraste com apenas 30\% no início dos anos 1950, segundo os dados do Instituto Brasileiro de Geografia e Estatística (IBGE). Mais que a expressão estatística dessa alteração na composição demográfica da população e do povoamento regional, os dados revelam uma tendência à formação de aglomerações urbanas como as principais bases de organização do território.

Para Becker (2001), essa constituição tem a ver com a formação de uma economia de fronteira na região, daí a autora analisar a formação de cidades na Amazônia a partir da necessidade de construção de uma rede urbana regional, que é lócus de atuação das instituições responsáveis por executar o projeto de integração do qual a região foi objeto na segunda metade do século XX.

Para Machado (1999), essa evolução recente da urbanização demonstra a gênese de adensamentos ou "condensações" urbanas, posto que, trata-se do adensamento do número de cidades em determinadas regiões do sistema de povoamento. Nesse caso, é necessário considerar que, para o estudo dos processos de urbanização, a presença desses adensamentos é tão importante quanto o aumento do tamanho e número de cidades ou mudanças na estrutura hierárquica.

Entretanto, pensando para além do adensamento urbano e suas repercussões estatísticas e demográficas, no período mais recente, uma nova qualidade surge na dinâmica da urbanização do espaço regional, que se pode classificar como a emergência de metrópoles regionais em consonância com o movimento mais geral de metropolização do espaço brasileiro no final do século XX e início do século XXI.

Nesse caso, acompanhando os processos socioespaciais de metropolização regional, verifica-se que esses se mostram como uma tendência da urbanização amazônica, mas isso não quer dizer que tais processos tenham configurações homogêneas. Ao contrário, a região tem aglomerados metropolitanos ${ }^{1}$ que apresentam características diversas, seja ao tipo de

\footnotetext{
${ }^{1}$ Em trabalho anterior - Veloso (2015) -, identificou os elementos que fazem de Belém, Manaus e São Luís metrópoles de referência para a região amazônica. Para o escopo deste artigo, considera-se apenas a análise de São Luís, bem como sua relação com a Amazônia oriental. 
dinâmica econômico-espacial que potencializa e intensifica o processo de metropolização, seja no que tange a paisagem produzida como expressão de processos mais profundos.

Partindo desse pressuposto, o de uma diferenciação metropolitana regional, apresenta-se como referência de análise a metrópole de São Luís como lócus empírico da presente análise. A escolha especifica desse espaço urbano-metropolitano e, em particular sua inserção na região amazônica, leva em conta elementos da formação histórica e regional da Amazônia do Maranhão, desde a configuração territorial adotada no século XVIII, como a existência do estado do Maranhão e Grão-Pará, que tiveram grande repercussão na produção do espaço.

Além disso, mais recentemente, na segunda metade do século XX, parte significativa das políticas de integração e desenvolvimento adotadas para a região, tiveram como elemento a intensificação da relação entre o oeste maranhense e o interior amazônico, especialmente quando se considera a dinâmica da mineração industrial, os programas de desenvolvimento e os projetos logísticos que a acompanharam, causando repercussões diretas na produção do espaço urbano regional e a consequente metropolização do espaço.

Torna-se importante destacar ainda, que as mudanças no espaço dessa aglomeração não são resultado somente de movimentos estruturais gerais da integração da região ao território nacional e mesmo a inserção nos fluxos da globalização. Há um vetor de transformação resultante da história de constituição desses espaços no contexto da urbanização regional, a ponto de identificarmos elementos que as diferenciam substancialmente. Trata-se, portanto, de compreender os elementos constituintes da estruturação intraurbana de São Luís e os desdobramentos dessa estrutura na porção oriental da Amazônia.

\section{REGIÃO E FORMA URBANA: A DINÂMICA HISTÓRICA DE SÃO LUÍS NA AMAZÔNIA ORIENTAL}

Urbanização da sociedade e do território (SANTOS; SILVEIRA, 2001), urbanização extensiva (MONTE-MÓR, 2003), metropolização do espaço (LENCIONI, 2008). Conceituações que, se não dão conta de toda a complexidade urbana regional, são importantes para compreender a intensidade do fenômeno na Amazônia contemporânea. É, portanto, a partir desses conceitos que passamos a visualizar a expressão dos processos de metropolização na região a partir de São Luís.

Por um lado, a escolha dessa metrópole está associada a um recorte metodológico. Em estudos acerca da realidade amazônica, as cidades de Belém e Manaus, são geralmente as 
duas referências mais conhecidas, tendo em vista seu significado na constituição da rede urbana e sua importância como referências no processo de integração da Amazônia no pós1960.

Entretanto, para além dessas importantes aglomerações, dois elementos ratificam a escolha de São Luís como metrópole amazônica, posto que, embora alguns recortes políticosadministrativos considerem o Maranhão, ou ao menos a porção leste do estado, como componente da região Nordeste brasileira ${ }^{2}$, há elementos da história e da geografia regional que justificam sua inclusão no contexto amazônico.

O primeiro desses elementos é a história regional estabelecida desde o período colonial, com a existência da configuração político-territorial do Estado do Maranhão e Grão-Pará, estrutura administrativa que atuava na porção centro-norte do território colonial na América portuguesa. A existência dessa estrutura administrativa, que tinha em Belém e São Luís as duas referências urbanas mais importantes ajudam a consolidar a aproximação políticocultural entre o interior amazônico e o meio-norte do território.

De fato, o Estado do Maranhão, criado por carta régia em 1620, enquanto unidade administrativa separada do Brasil e diretamente subordinada a Lisboa, correspondia ao propósito de garantir a posse dos vastos domínios do Norte. A carta régia de 13 de junho de 1621 confirmou a criação do Estado do Maranhão e Grão-Pará, com sede em São Luís, e a sua independência administrativa do Estado do Brasil. Além disso, a conveniência de se criar um governo separado do Estado do Brasil derivava da necessidade da defesa territorial dos primeiros núcleos populacionais, estabelecidos nas costas do Maranhão e do Pará (SANTOS, 2008, p. 21).

Essa configuração político-administrativa do Estado do Maranhão e Grão-Pará, contou ainda com uma estrutura econômica distinta do restante do território colonial, com uma base econômica assentada na coleta e extração de produtos, e não na economia agroexportadora do litoral nordestino, a exemplo da exploração das "Drogas do Sertão". Outro elemento é a diferenciação em relação ao restante da colônia, a mão de obra era majoritariamente indígena e catequizada e não escrava negra. Essas diferenciações provocavam, portanto, a necessidade de formas distintas de administração territorial, por parte do Império Português, como relata Santos (2008):

Do ponto de vista administrativo, a existência de uma unidade administrativa no Norte, independente do governo de Salvador, representou uma medida centralizadora

\footnotetext{
${ }^{2}$ De fato, na divisão político-administrativa produzida pelo IBGE o Maranhão está incluído na Região Nordeste do Brasil. Outras regionalizações utilizadas, como a divisão geoeconômica, atestam a porção Oeste do estado do Maranhão como componente da região amazônica, em virtude de similaridades socioeconômicas.
} 
da metrópole. A necessidade de colonizar um vasto território na América - ao longo do século XVII as suas fronteiras seriam paulatinamente ampliadas -, levou à percepção de que a geografia não permitia a existência de apenas um centro administrativo. Ademais, as disparidades regionais deviam ser levadas em conta. Os problemas do Estado do Maranhão em grande parte não eram os mesmos do CentroSul da América Portuguesa (SANTOS, 2008, p. 28).

Apesar das tentativas de criação de duas unidades separadas já no século XVII, houve durante o período pombalino ${ }^{3}$ um reforço a esses laços. Primeiro com a criação da Companhia Geral de Comércio, empresa colonial que tornava muito próximas as realidades das duas cidades, Belém e São Luís. Em segundo a partir da mudança institucional para o Estado do Grão-Pará e Maranhão, com a mudança de sede de São Luís para Belém em 1751, que assim reforçava a existência de único projeto econômico para a região, nesse momento a empresa comercial monopolista no século XVIII.

Este elo - a empresa comercial - orientava um projeto regional no período colonial que não foi perdido, mesmo com o esgotamento da empresa comercial monopolista e a posterior criação de duas unidades político-administrativas distintas em 1774, o Estado do Grão-Pará e Rio Negro e o Estado do Maranhão e Piauí, com a fragmentação da unidade administrativa. Apesar disso, a continuidade de laços econômicos e fluxos migratórios manteve a proximidade entre o Maranhão e o interior do vale amazônico. Já no período da economia da borracha, por exemplo, entre o final do século XIX e o início o século XX, a maior parte dos fluxos de força de trabalho para o interior da floresta eram provenientes dos estados do Nordeste, notadamente o Ceará e, em seguida o Maranhão. Para Benchimol:

[...] os nordestinos, especialmente os 'cearenses', foram os pioneiros do povoamento amazônico, atraídos pelo ciclo econômico da borracha a partir de meados do século XIX, principalmente durante as décadas de 1877 e 1888, como flagelados e retirantes, em direção aos seringais, até a década de 1920 e 1930 quando ocorreu a depressão econômica, interrompendo o fluxo, que até então era constante. Dados demográficos da população amazônica, neste período, desde 1872 com 332.847 habitantes a 1920 quando foram recenseados 1.439 .052 habitantes, demonstram que houve um crescimento de $332,0 \%$, seguido de uma estagnação em decorrência da crise do primeiro ciclo da borracha, cujas exportações diminuíram devido à ascensão do cultivo de seringais na Malásia (BENCHIMOL, 1991).

\footnotetext{
${ }^{3}$ O período pombalino compreende a administração do Marquês de Pombal (1755 - 1777), marcada por reformas políticas, econômicas e administrativas nas colônias. No Estado do Grão-Pará e Maranhão, essas reformas compreenderam: a) transferência da capital do Grão-Pará e Maranhão de São Luiz para Belém; b) fim do poder eclesiástico com a expulsão dos jesuítas e confisco dos seus bens; c) introdução da mão de obra escrava negra; d) expansão da agricultura comercial e da pecuária.
} 
Portanto, esses elementos da história regional tornam comuns em amplo aspecto a formação territorial maranhense com a região amazônica. Além disso, o segundo elemento dessa configuração é mais recente, data da segunda metade do século XX com o estabelecimento das políticas de integração nacional e refere-se à divisão regional que se convencionou chamar de Amazônia Legal, oficialmente instituída em 1953 pela Lei n. ${ }^{\circ} 1.806$, com $61 \%$ do território brasileiro. Esta área tinha como objetivo definir a delimitação da região de planejamento captadora de incentivos fiscais com o propósito de promoção do seu desenvolvimento. Oficialmente não estava limitada por características geológicas, morfoclimáticas ou de vegetação, mas para orientar o planejamento econômico na região e sua integração ao restante do País. Posteriormente, os limites da Amazônia Legal foram alterados ${ }^{4}$ várias vezes em consequência de mudanças na divisão política do País.

Nesse sentido, considera-se que a opção por elencar o Oeste do Maranhão como componente da região de planejamento denominada Amazônia Legal, retoma em certos aspectos a contiguidade histórica da formação socioespacial desse estado com a região amazônica. Assim, considera-se que São Luís faz parte do processo de metropolização do espaço amazônico porque: a) sua história urbana e regional é comum à produção do espaço amazônico, desde o início da ocupação no século XVII até a atualidade dos programas de integração do século XXI; b) o padrão de metropolização recente advém da inserção nos projetos de modernização do território regional através da instalação de grandes projetos econômicos e causa repercussões nas três aglomerações urbanas mais importantes, Belém, Manaus e São Luís. Assim, quando consideramos este perfil regional e o associamos a base demográfica, conforme o mapa 01, a importância de São Luís na rede urbana regional, em conjunto com Belém e Manaus:

\footnotetext{
${ }^{4}$ Os limites da Amazônia Legal foram alterados desde sua criação em 1953, em decorrência das mudanças na divisão do território brasileiro. Originalmente era composta pelos Estados do Amazonas, Pará, Rondônia, Acre, norte de Goiás (que deu origem ao Estado do Tocantins, em 1988), Maranhão (parte oeste), Mato Grosso (parte Norte, que continua a fazer parte da Amazônia Legal, mesmo depois da divisão do Estado e criação do Mato Grosso do Sul) e os territórios federais do Amapá (atual Estado do Amapá), de Rio Branco (atual Estado de Roraima) e do Guaporé (atual Estado de Rondônia). 


\section{Mapa 01. Amazônia Legal: população das cidades (2010)}
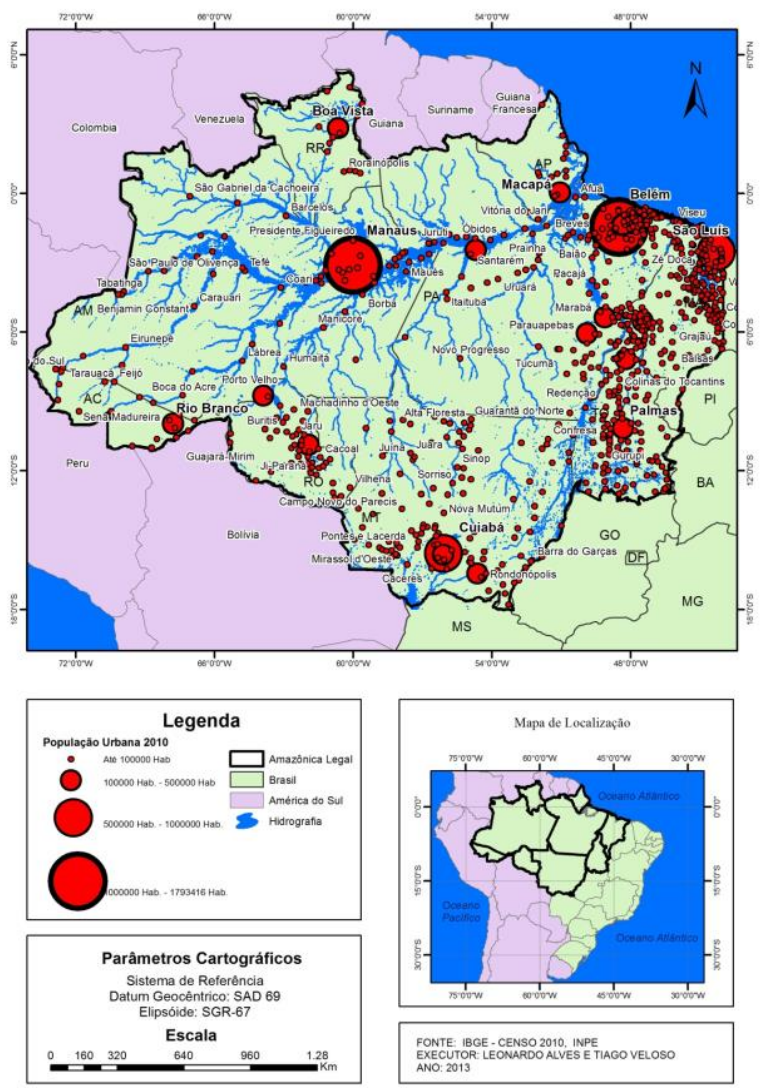

Quando considerados em conjunto com as tendências de regionalização, especialmente a definida por Becker $(2001)^{5}$, percebe-se a existência das metrópoles na área de influência de cada uma das sub-regiões destacadas, o que revela uma particularidade da metropolização regional, a existência de um elo entre as dinâmicas sub-regionais e as formações das aglomerações. Este elo entre as metrópoles e as sub-regiões está representado no mapa 02, que destaca a complementaridade resultante entre as dinâmicas sub-regionais e as concentrações metropolitanas, o que torna possível reconhecer cartograficamente esses espaços como as três maiores aglomerações na Amazônia Legal ${ }^{6}$.

\footnotetext{
${ }^{5}$ A Amazônia Oriental e Meridional que corresponde ao arco povoado a leste e sul da floresta, respectivamente as áreas desmatadas do sudeste do Pará e agroindústria do cerrado matogrossense, com expansão para o Tocantins e Rondônia, e cujos limites seriam Açailândia no Maranhão e Cacoal em Rondônia. A Amazônia Central, estendendo-se do nordeste do Pará à rodovia Porto Velho-Manaus-Venezuela. Passível de expansão da agricultura capitalizada, como pode ser o caso da soja na Cuiabá-Santarém, no vale do Madeira, no rio Juma, contém grande proporção de terra indígenas e unidades de conservação, o que lhe atribui grande vulnerabilidade. A Amazônia Ocidental, unidade ainda marcada pelo ritmo da natureza. (BECKER, 2001, p. 156-157).

${ }^{6}$ Considerando os números absolutos da população das três metrópoles analisadas: Região Metropolitana de Belém: 2.101.883 de habitantes; Região Metropolitana de Manaus: 2.021.181 de habitantes; Região Metropolitana de São Luís: 1.261.382 de habitantes (IBGE, 2010). 


\section{Mapa 02. Amazônia: metrópoles e complexos sub-regionais}
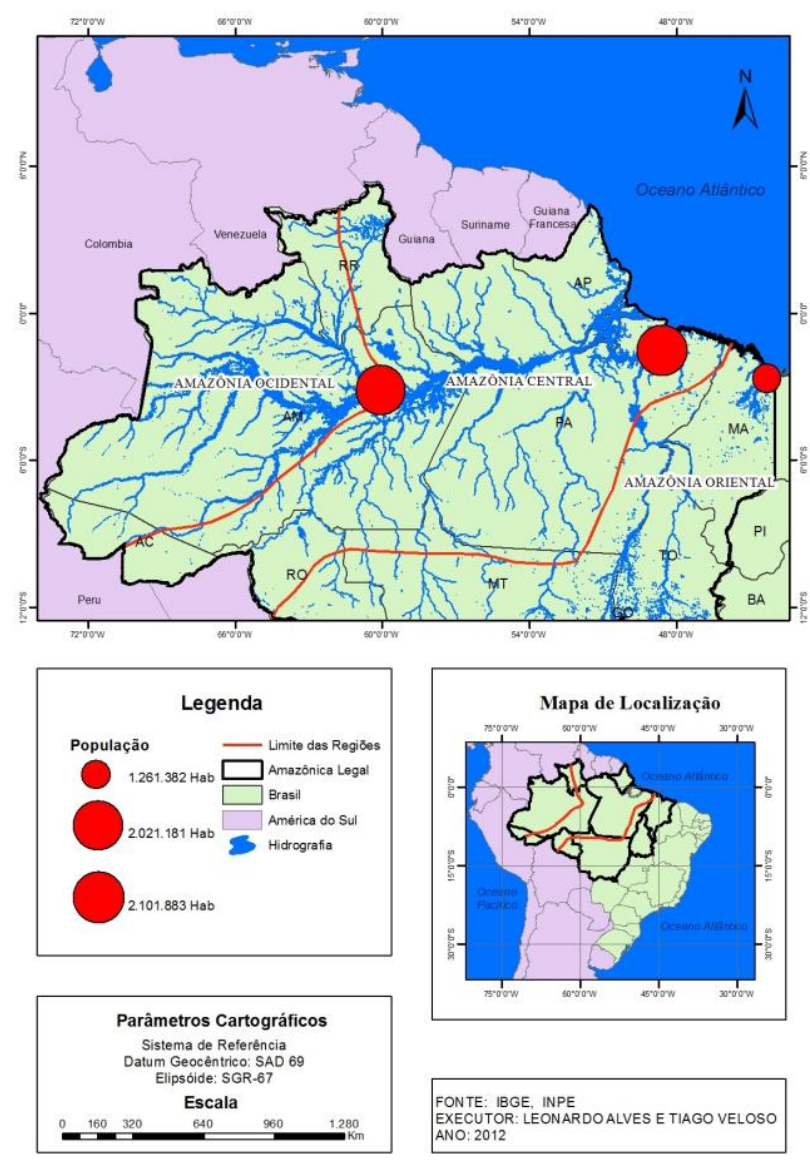

Nesse caso, considerando essa particularidade da porção sub-regional oriental, é São Luís que revela diferenciações quanto ao seu processo de metropolização. A sub-região na qual se insere essa metrópole tem como características a implantação de grandes projetos logísticos para compor a base de extração mineral como os promovidos pela Companhia Vale do Rio Doce (hoje VALE), o ALUMAR (Alumínios do Maranhão S. A.), que criou a expectativa de desenvolvimento econômico do Estado do Maranhão, assim como do Município de São Luís, refletindo a ideia de desenvolvimento socioeconômico da cidade em consequência dos projetos.

De fato, São Luís, é a metrópole que apresenta a maior taxa de crescimento demográfico dos anos 1990 em diante, chegando na década de 2000 à condição de "cidade milionária" (SANTOS, 1993), ou seja, com um milhão de habitantes. Essa condição inclui tentativas de institucionalização de uma região metropolitana que de fato, é efetivada no final 
da década de 1990 e início dos anos $2000^{7}$. A tabela 01 revela como se distribui a população nos municípios que compõem a região metropolitana:

Tabela 01 - Região Metrop. Grande São Luís: população absoluta por municípios (2010-2013)

\begin{tabular}{c|c|c|c}
\hline Municípios & $\begin{array}{c}\text { População absoluta } \\
\mathbf{2 0 0 0}\end{array}$ & $\begin{array}{c}\text { População absoluta } \\
\mathbf{2 0 1 0}\end{array}$ & $\begin{array}{c}\text { População absoluta } \\
\mathbf{2 0 1 3}\end{array}$ \\
\hline São Luís & 870.028 & 1.014 .837 & 1.053 .922 \\
\hline São José do Ribamar & 107.384 & 163.045 & 170.423 \\
\hline Paço do Lumiar & 76.188 & 105.121 & 113.378 \\
\hline Bacabeira & - & 14.925 & 15.982 \\
\hline Rosário & - & 39.576 & 40.983 \\
\hline Santa Rita & - & 32.366 & 34.710 \\
\hline Raposa & 17.088 & 26.327 & 28.543 \\
\hline Alcântara & - & 21.851 & $\mathbf{6 . 7 9 4 . 3 0 1}$ \\
\hline Estado do Maranhão & & $\mathbf{6 . 5 7 4 . 7 8 9}$ &
\end{tabular}

Fonte: IBGE (2010, 2014).

Organização: Tiago Veloso dos Santos.

Assim, as repercussões no plano regional com dinamização da economia local, trouxe mudanças na produção do espaço. Destaca-se a concentração da riqueza produzida na capital, que centraliza quase $40 \%$ do PIB estadual, discrepância notável quando comparada aos outros municípios que compõem a região metropolitana. Nenhum deles, a exceção de São Luís, contribui com proporções significativas do PIB estadual (tabela 02).

Tabela 02 - Região Metrop. Grande São Luís - Participação do PIB dos municípios (PIB a preço de mercado - R\$ 1.000)

\begin{tabular}{c|c|c|c|c}
\hline Municípios & $\begin{array}{c}\text { PIB (R\$ 1.000) - } \\
\mathbf{2 0 0 7}\end{array}$ & $\begin{array}{c}\text { Participação } \\
\text { Relativa (\%) }\end{array}$ & $\begin{array}{c}\text { PIB (R\$ 1.000) - } \\
\mathbf{2 0 1 0}\end{array}$ & $\begin{array}{c}\text { Participação } \\
\text { Relativa (\%) }\end{array}$ \\
\hline São Luís & 12.272 .006 & 38,83 & 17.915 .048 & 39,59 \\
\hline São José do Ribamar & 365.003 & 1,15 & 538.180 & 1,19 \\
\hline Paço do Lumiar & 195.630 & 0,62 & 336.915 & 0,74 \\
\hline Bacabeira & 98.516 & 0,31 & 117.822 & 0,26 \\
\hline Rosário & 94.026 & 0,30 & 145.548 & 0,32 \\
\hline
\end{tabular}

\footnotetext{
${ }^{7}$ A Região Metropolitana da Grande São Luís (RMGSL), foi oficialmente criada a partir de Lei estadual 038 de 1998. Sua composição original foi formada pelos Municípios de São Luís, Raposa, São José do Ribamar e Paço do Lumiar. Em 2003, nova redação, sob a Lei Complementar Estadual 069, inclui o Município de Alcântara. Mais recentemente, em 2013, os Municípios de Bacabeira, Rosário e Santa Rita foram incorporados a RMGSL, totalizando neste momento oito municípios constituintes. De fato, a discussão sobre a criação de uma Região Metropolitana no Maranhão existe desde a década de 1970, promovida por setores do governo do Estado do Maranhão, acompanhando o cenário de criação das regiões metropolitanas em plano nacional. Segundo Ferreira (1999), desde 1974 a Lei Delegada no 48 pretendia definir diretrizes comuns para os três municípios até então existentes na Ilha do Maranhão (São Luís, São José do Ribamar e Raposa), imediatamente posterior ao momento de criação das primeiras regiões metropolitanas no Brasil. Entretanto, apesar dessas discussões internas, não houve avanços nesse período. Somente a partir do final da década de 1980, com a Constituinte do Estado do Maranhão é criada a Região Metropolitana da Grande São Luís, determinando que sua abrangência, organização e funções fossem definidas através de lei complementar, o que foi realizado em 1998. Para compreender o processo de institucionalização da Região Metropolitana da Grande São Luís, ver Cordeiro (2013; 2014) e Cordeiro e Diniz (2009).
} 
Revista de Geografia (Recife) V. 34, No. 3, 2017

\begin{tabular}{c|c|c|c|c}
\hline Santa Rita & 72.644 & 0,23 & 106.281 & 0,23 \\
\hline Raposa & 67.943 & 0,21 & 107.908 & 0,24 \\
\hline Alcântara & 55.432 & 0,18 & 74.901 & 0,17 \\
\hline $\begin{array}{c}\text { Região Metropolitana da } \\
\text { Grande São Luís }\end{array}$ & 12.221 .200 & 41,83 & 19.342 .603 & 42,54 \\
\hline Estado do Maranhão & $\mathbf{3 1 . 6 0 6 . 0 2 6}$ & $\mathbf{1 0 0}$ & $\mathbf{4 5 . 2 5 5 . 9 4 2}$ & $\mathbf{1 0 0}$ \\
\hline
\end{tabular}

Fonte: Maranhão (2012; 2013).

Organização: Tiago Veloso dos Santos.

Elemento importante desse fenômeno de metropolização regional é a relação da aglomeração com a mina de ferro de Carajás (VICENTINI, 2004). Mesmo estando localizada no Estado do Pará, a exploração econômica da mina de ferro de Carajás imprimiu uma dinâmica territorial importantíssima para o oeste do Estado do Maranhão, por meio do escoamento do minério de ferro pela ferrovia de Carajás e pelo Porto de Itaqui. Trata-se da primeira grande ferrovia moderna na Amazônia, com $890 \mathrm{~km}$ de extensão, que atravessa parte do território da bacia amazônica, ligando São Luís, no litoral atlântico, à serra dos Carajás no sudeste paraense (VICENTINI, 2004).

Em todo o percurso, da metrópole de São Luís à mina de Carajás, atravessando o Estado do Maranhão até a reserva mineral de Carajás, no Pará, criaram-se novas condições de apropriação territorial, fazendo com que surgissem vários núcleos urbanos e povoados ao longo da ferrovia na região do Médio Vale do Pindaré, no Maranhão; e no trecho entre Marabá e Carajás, no Pará (VICENTINI, 2004, p. 193).

A dinâmica da porção oeste do Estado do Maranhão, portanto acompanha em grande parte as políticas territoriais estabelecidas para o Estado do Pará, responsável por uma dinâmica migratória intensa e a constituição de uma fronteira de expansão capitalista, pela estruturação de uma sub-região conflituosa e de rápidas transformações sociais e econômicas, assim como por estimular o processo de metropolização verificado em São Luís, daí reconhecermos essa parte do território como integrante da dinâmica regional amazônica. Em São Luís, os elementos da cidade corporativa (SANTOS, 1993) associada aos grandes empreendimentos se fazem presentes:

A Alumar instalou junto à produção uma cidade empresarial e no interior da cidade de São Luís um condomínio para seus principais dirigentes, verdadeiro contraste com a cidade, definindo um espaço disciplinado e antagônico, com escolas e clube privado, de acesso absolutamente restrito (VICENTINI, 2004, p. 197).

Para além do grande empreendimento e do porto conectado à ferrovia, a cidade cresceu incorporando à sua malha urbana municípios vizinhos que passam a formar, mesmo que às vezes, de forma descontínua, uma malha urbana única, posto que, no aspecto da formação do 
espaço intraurbano é somente entre o final dos anos 1960 e os anos 1970 que a cidade adquire um traçado urbano mais complexo em relação a sua origem colonial, o que inclui a expansão dos limites territoriais urbanos.

A partir dessas considerações, é possível afirmar que a metrópole em questão exerce influência significativa na porção oriental da Amazônia atual, definindo inclusive um dinâmico complexo metrópole - sub-região, articulado a um tipo de metropolização associado as tendências demográficas, espaciais e econômicas dessa porção. Essa relação, como veremos, justifica o padrão atual de estruturação da aglomeração metropolitana em período recente.

\section{METRÓPOLE E REGIÃO: O ESPAÇO INTRA-URBANO DE SÃO LUÍS COMO EXPRESSÃO DA RELAÇÃO COM A REGIÃO.}

Em São Luís, a paisagem de uma metrópole moderna ainda é contraditada pela existência e valorização de um centro histórico que revela a herança da colonização portuguesa e da influência francesa. Para Burnnet (2008), a paisagem de São Luís é marcada por dois tipos de urbanização: a tradicional, originada da conquista portuguesa do século XVII, e a modernista, implantada no último quartel do século XX com a conquista do litoral da ilha ${ }^{8}$. Cada um destes padrões "representam dois modelos urbanos contrastantes nos seus modos de apropriação espacial do território, distribuição de funções, localização da população e tratamento do meio ambiente e recursos naturais" (BURNNET, 2008, p. 16-17).

A paisagem da urbanização tradicional está associada à história de São Luís, desde o século XVII até a década de 1950 do século XX, período no qual a cidade possuía uma população urbana da ordem de 120.000 habitantes e continuava "isolada" do resto do País: suas ligações eram feitas através do precário porto de São Luís e do aeroporto. As rodovias não existiam e as áreas de ocupação periféricas estavam localizadas nas bacias do Rio Anil e do Rio Bacanga. Isso se dava porque a dinâmica econômica do Maranhão até a primeira metade do século XX está associada à produção agrícola no interior do Estado. A mudança de

\footnotetext{
${ }^{8}$ Essa compreensão de duas paisagens proposta por Burnnet (2008), obviamente não esgotam uma compreensão acerca da produção do espaço urbano em São Luís. É possível apontar a existência de paisagens que, a princípio, não estão contidas na interpretação do autor, mas que foram produzidas a partir das contradições estimuladas pela modernização do espaço em São Luís, especialmente as paisagens relacionadas a fenômenos destacados no escopo deste texto, como a intensificação da segregação socioespacial e a dispersão do espaço urbanometropolitano da Grande São Luís. 
orientação dos investimentos públicos e privados proporcionados pela integração regional a partir dos anos 1960 vai mudar a perspectiva espacial do Estado, que segundo Ferreira (1999):

[...] revelam o dinamismo da organização espacial do Estado do Maranhão tendo em vista suas repercussões sobre a rede urbana e alocação de investimentos nacionais e internacionais os quais indicam: 1) São Luís tem se constituído no elemento definidor da organização espacial do Estado; 2) o epicentro econômico migra dos vales úmidos do leste - século XVII até 1950 - para as áreas de implantação de projetos de colonização dirigida - 1960 e Programa Grande Carajás (oeste) - 1980 - além do polo agrícola (no sul do Estado) - 1985; 3) a mobilidade territorial da força de trabalho acompanhou esse epicentro, o que coincide com as mudanças no centro de gravidade de população do Maranhão no período entre 1872-1980 identificadas pelo IBGE (FERREIRA, 1999, p. 22).

Essas mudanças no plano regional associadas às novas diretrizes de ocupação do espaço amazônico provocaram repercussões na ordem intraurbana de São Luís, que passou a crescer recebendo contingentes de força de trabalho, conforme a tabela 03.

Tabela 03. São Luís: evolução demográfica (1920 - 2010)

\begin{tabular}{|c|c|}
\hline ANO & População Total \\
\hline 1920 & 52.929 \\
\hline 1940 & 74.675 \\
\hline 1950 & 119.785 \\
\hline 1960 & 158.292 \\
\hline 1970 & 265.486 \\
\hline 1980 & 449.433 \\
\hline 2091 & 696.371 \\
\hline 2010 & 870.028 \\
\hline
\end{tabular}

Fonte: IBGE (2010).

Organização: Tiago Veloso dos Santos

Segundo Luz (2004), é na década de 1960 que o Estado passa a ser o facilitador - por meio de instrumentos jurídicos, políticos e econômicos - da criação de condições favoráveis para as grandes empresas investirem com condições mínimas de terra e de mão de obra barata. Para garantir que o processo não tivesse obstáculos levou-se a cabo um amplo processo de modernização da economia, cujo traço principal estava baseado nos grandes projetos e no apoio das elites locais e nacionais ao capital nacional e estrangeiro (PORTELA, 2011).

Portanto, a modificação da produção do espaço urbano da cidade se deu a partir do desenvolvimento das instalações logísticas para apoio aos projetos de exploração mineral, intensificando as possibilidades de ocupação e de ampliação da malha urbana de São Luís. É a chegada dos projetos econômicos e os impactos territoriais derivados que provocam mudanças no espaço urbano de São Luís. Ou seja, define-se a formação recente do espaço urbano de São Luís a partir do desenvolvimento de dinâmicas regionais após a primeira 
metade do século $\mathrm{XX}$, posto que a cidade até então estava limitada em termos de espaço urbano, reflexo da economia agrícola e focada em outros eixos que não o baseado na capital. A partir de 1970, com o desenvolvimento dos programas regionais, a cidade passa a ser objeto de mudanças, provocados pelas repercussões dos empreendimentos regionais localizados em São Luís, orientando a perspectiva da metropolização de seu espaço.

Acompanhando o crescimento demográfico, uma das consequências dos investimentos é que São Luís adquire gradativamente um novo traçado, pois a malha urbana foi expandida a partir do rompimento do bloqueio pelos rios Bacanga e Anil, com as construções de barragem do Bacanga e da Ponte do São Francisco (RIBEIRO JUNIOR, 1991, p. 24-25), o que ocasionou crescimento da ocupação da área do município em relação ao que havia sido ocupado desde sua gênese. Como consequência dessa transformação, houve a expansão do tecido urbano que teve como marcos para a ocupação do território, a construção da Ponte José Sarney, que encurtou o caminho da cidade para as praias, enobrecendo a área litorânea e a edificação da barragem sobre o Rio Bacanga, ambos concluídos no ano de 1970. Abriram-se assim, duas frentes no espaço urbano de São Luís: a) ao norte, em direção do litoral balneário, área nobre da cidade; b) a sudoeste, de fraca densidade demográfica, que se tornaria zona de ocupação periférica, abrigando parcela da população pobre e facilitando o acesso entre o Porto de Itaqui e a zona central. Além dessas duas frentes de expansão do espaço, é necessário atentar para a contínua ocupação das áreas centrais da ilha, local onde foram construídos alguns dos conjuntos habitacionais importantes, como Cidade Operária, COHAB, COHATRAC e que compõem o núcleo metropolitano mais adensado, conforme apresentado no quadro 02 (Estrutura Metropolitana).

A abertura dessas duas frentes ampliou a oferta de terra e provocou modificações, destacando-se o aumento das ocupações de terras para a construção de moradias populares. Os processos migratórios da força de trabalho do campo para a cidade se intensificou, posto que contingentes populacionais passaram a dirigir-se para São Luís em busca de melhores condições de vida e emprego que acreditava-se estar associada ao desenvolvimento das atividades industriais.

Esse surto industrial, orientado pelos investimentos de integração regional, trouxe mudanças na estrutura socioespacial da cidade. No período entre 1970 e 1980 instalaram-se efetivamente grandes plantas industriais, como as empresas Alumínio do Maranhão S. A. (ALUMAR); a Companhia Vale do Rio Doce (CVRD); e a Celulose do Maranhão (CELMAR). 
Apesar de o setor industrial ter passado por mudança no perfil e crescimento substantivo e a constituição desse setor ter tido grande influência nas mudanças urbanas, ele tem um peso ainda pequeno, regional e nacionalmente em termos econômicos e é altamente especializado e concentrado em poucos produtos (commodities minerais) e localizações. $\mathrm{O}$ setor se concentra na Região Metropolitana de São Luís e em alguns outros municípios ligados à indústria de transformação como Açailândia (fabricação de ferro gusa e madeira laminada), Imperatriz (fabricação de bebidas e fertilizantes agricolas) e Caxias (fabricação de bebidas). A tabela 04 mostra como em termos comparativos a indústria não foi o setor que mais cresceu no Maranhão, apesar dos investimentos na mineração advindas do Projeto Carajás na década de 1980.

Tabela 04. Maranhão: participação da Indústria no PIB

\begin{tabular}{|c|c|c|c|}
\hline Ano & Agropecuária (\%) & Indústria (\%) & Serviços (\%) \\
\hline 1985 & 27,21 & 18,34 & 54,45 \\
\hline 1995 & 23,00 & 20,00 & 58,00 \\
\hline 2004 & 18,16 & 17,38 & 64,45 \\
\hline 2008 & 22,19 & 16,96 & 60,95 \\
\hline 2010 & 17,20 & 15,70 & 67,10 \\
\hline
\end{tabular}

Fonte: IBGE (2010) Maranhão (2012).

Assim, ainda que implantação desses grandes projetos logísticos - apresentados no quadro 01 - e o comércio surgido em decorrência deles tenham sido os fatores do crescimento de São Luís, eles não tem capacidade de fornecer grandes perspectivas de emprego à mão de obra que se dirigia para a metrópole, pela sua própria natureza de objetos que possibilitam o vazamento de riqueza em direção ao exterior, e não necessariamente a sua internalização e distribuição.

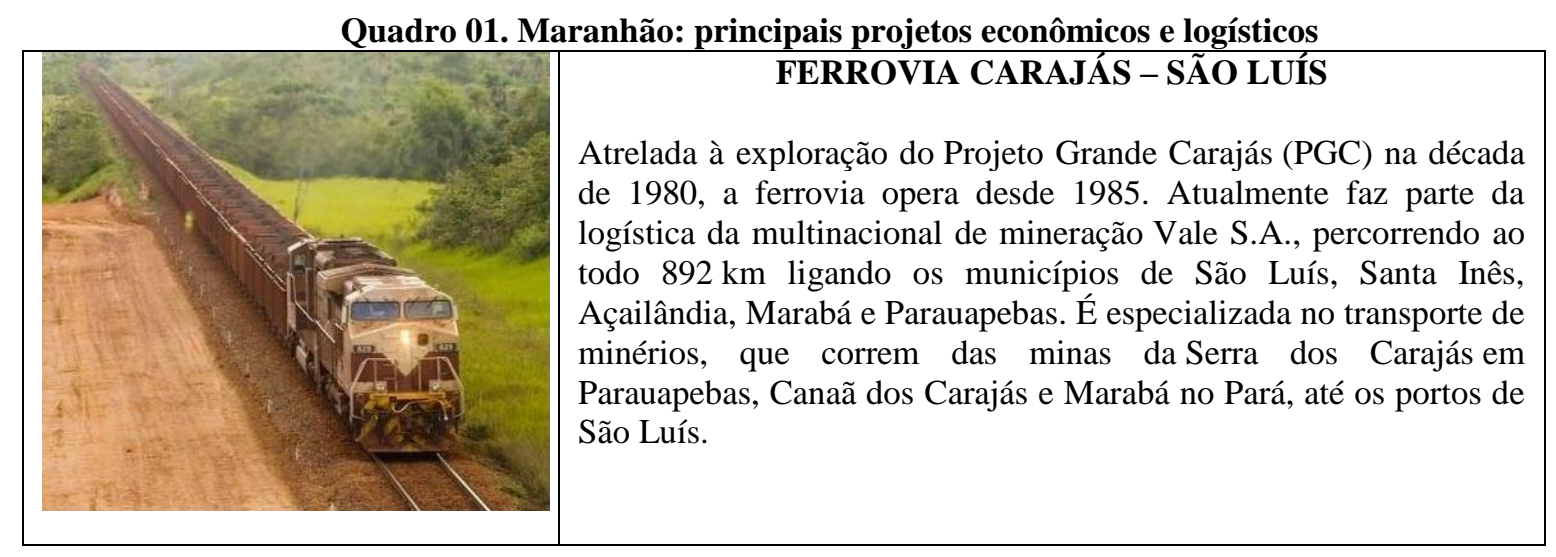




\begin{tabular}{|c|c|}
\hline & $\begin{array}{l}\text { COMPLEXO ALUMAR E PORTO GRANDE } \\
\text { O Consórcio de Alumínio do Maranhão (Alumar) é um complexo } \\
\text { de produção de alumínio primário e alumina. Inaugurado em 1984, } \\
\text { é formado pelas empresas Alcoa, BHP Billiton e Rio Tinto. O } \\
\text { Terminal Portuário é privativo da Alumar e está localizado na Baía } \\
\text { de São Marcos em São Luis. No porto acontece o desembarque das } \\
\text { matérias-primas e dos insumos usados na produção do Alumínio. }\end{array}$ \\
\hline & $\begin{array}{l}\text { PORTO DE ITAQUI } \\
\text { Localizado na Baía de São Marcos, o Porto de Itaqui atende à } \\
\text { cidade e o Estado do Maranhão, e possui uma das maiores } \\
\text { profundidades de porto do mundo, com cerca de vinte e dois } \\
\text { metros. }\end{array}$ \\
\hline 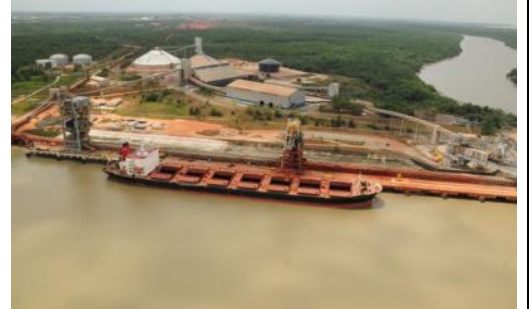 & $\begin{array}{l}\text { PORTO DA PONTA DA MADEIRA } \\
\text { O Terminal Marítimo da Ponta da Madeira é } \\
\text { um porto privado pertencente à Empresa VALE, adjacente ao porto } \\
\text { de Itaqui, na cidade de São Luís. Destina-se principalmente à } \\
\text { exportação de minério de ferro trazido do projeto Serra dos Carajás, } \\
\text { no Pará. }\end{array}$ \\
\hline
\end{tabular}

Fonte: Governo do Estado do Maranhão.

Organização: Tiago Veloso dos Santos.

A atuação de empresas públicas e privadas que encontraram em São Luís as condições necessárias para seus empreendimentos são fundamentais para se compreender esse momento de metropolização da cidade. Com a expansão do espaço urbano, ocorreram mudanças no padrão de ocupação das classes sociais, que até a primeira metade do século XX, estavam limitadas às proximidades do centro histórico.

Houve a concentração de bairros de alta renda em torno do centro histórico e em direção ao norte da Ilha, com a interligação entre o centro e a área das praias possibilitada pela Ponte José Sarney, causando enobrecimento de alguns bairros centrais, nos quais os negócios imobiliários ganharam projeção na década de 1980, caracterizando-se pela verticalização. Paralelamente, acelerou-se a ocupação por populações de menor poder aquisitivo nas áreas alagadiças e nos manguezais. Esse crescimento direcionou-se para três vetores:

1) norte da Ilha, compreendendo a orla marítima e as áreas situadas entre os conjuntos habitacionais recentemente implantados nas décadas de 1980 e 1990;

2) leste da Ilha, acompanhando a ligação rodoviária com os outros dois municípios; 
3) direção sul, acompanhando a ligação rodo-ferroviária da Ilha com o continente (LUZ, 2004).

De fato, é a partir desse momento que se configura gradativamente uma estrutura metropolitana em São Luís. Tal estrutura é acompanhada de segregação social pela diferenciação de uso dos setores da cidade e na intensificação do surgimento de áreas de ocupação de classes de menor renda. Nesse caso, chama atenção, que das 49 áreas de ocupação produzidas no período destacado na tabela 05,15 estão localizadas no município de São José do Ribamar, 11 em Paço do Lumiar e 02 em Raposa. Enquanto os investimentos industriais e a habitação de classe média e alta concentravam-se no município de São Luís, as habitações populares e de classe média baixa vão sendo deslocadas para os municípios vizinhos, ou seja, a periferia metropolitana distante.

Tabela 05. Região Metropolitana de São Luís: ocupação por municípios (1930 - 1998)

\begin{tabular}{|c|c|c|c|c|c|}
\hline Ano & N. & São Luís & São José do Ribamar & Paço do Lumiar & Raposa \\
\hline 1930 & 01 & 01 & - & - & - \\
\hline 1950 & 01 & 01 & - & - & - \\
\hline $1960-1973$ & 06 & 06 & - & - & - \\
\hline $1974-1988$ & 33 & 27 & 05 & 01 & - \\
\hline $1989-1998$ & 49 & 22 & 15 & 11 & 02 \\
\hline
\end{tabular}

Fonte: Ferreira (1999)

Organização: Tiago Veloso dos Santos

Em período recente, a periferia metropolitana mais afastada, vem recebendo alguns empreendimentos imobiliários de classes média e média alta, o maior exemplo é a chegada do Alphaville São Luís. Localizado no município de Paço do Lumiar, nas proximidades dos limites municipais de São Luís, as margens da rodovia MA-201 e MA-202, que liga os municípios da Ilha ao centro de São Luís, o empreendimento aparece como uma possibilidade de suburbanização de classes de alta renda no interior da metrópole. A análise desses elementos nos leva a propor um quadro explicativo da estrutura metropolitana de São Luís com a seguinte configuração:

Quadro 02 - São Luís: Estrutura metropolitana

\begin{tabular}{|c|l|l|l|}
\hline Setores Principais & \multicolumn{1}{|c|}{ Subdivisões } & \multicolumn{1}{c|}{ Caracterização Principal } & \multicolumn{1}{c|}{ Municípios } \\
\hline $\begin{array}{c}\text { Núcleo } \\
\begin{array}{c}\text { Metropolitano } \\
\text { Ocupação antiga ao } \\
\text { norte }\end{array}\end{array}$ & Centro Histórico & $\begin{array}{l}\text { Bairros antigos com funções } \\
\text { comerciais, de serviços e } \\
\text { residencial. }\end{array}$ & São Luís \\
\cline { 2 - 4 } & Pericentrais & $\begin{array}{l}\text { Bairros antigos ou recentes } \\
\text { predominantemente de classes } \\
\text { médias e altas. }\end{array}$ & São Luís \\
\cline { 2 - 4 } & Periferia antiga & $\begin{array}{l}\text { Bairros residenciais de classes } \\
\text { populares e com infraestrutura } \\
\text { precária }\end{array}$ & São Luís \\
\hline Santos, 2017 & Áreas de & Bairros residenciais de classes & \\
\hline
\end{tabular}




\begin{tabular}{|c|c|c|c|}
\hline \multirow{2}{*}{$\begin{array}{c}\text { Ocupação recente } \\
\text { ao } \\
\text { Leste }\end{array}$} & $\begin{array}{l}\text { ocupação } \\
\text { consolidada }\end{array}$ & médias e populares. & São Luís \\
\hline & $\begin{array}{l}\text { Áreas de } \\
\text { expansão (vetores } \\
\text { de expansão MA- } \\
\text { 201, MA-202). }\end{array}$ & $\begin{array}{l}\text { Bairros residenciais recentes } \\
\text { de classes populares e com } \\
\text { infraestrutura precária, mas } \\
\text { com chegada de } \\
\text { empreendimentos de classe } \\
\text { alta. }\end{array}$ & $\begin{array}{l}\text { São José do } \\
\text { Ribamar } \\
\text { Paço do Lumiar } \\
\text { Raposa }\end{array}$ \\
\hline $\begin{array}{c}\text { Ocupação recente a } \\
\text { Oeste }\end{array}$ & Áreas Industriais & $\begin{array}{l}\text { Áreas destinadas aos portos e } \\
\text { aos grandes projetos } \\
\text { econômicos }\end{array}$ & São Luís \\
\hline
\end{tabular}

Organização: Tiago Veloso dos Santos.

Essa leitura nos permite afirmar que, na área central da metrópole, localiza-se boa parte das classes de mais alta renda, configurando um perfil de concentração dessas classes nas áreas centrais, geralmente dotadas da melhor infraestrutura urbana e de serviços. Esse núcleo metropolitano é elemento de destaque na produção do espaço urbano de São Luís, posto que é considerado um espaço de alto valor imobiliário, arquitetônico e histórico e com ramificações na atividade turística. A concentração das classes de mais alta renda próximas ao centro não impossibilita que pequenas frações dessa classe possam localizar-se fora deste setor, o que explica a tendência de suburbanização, representada pela existência de empreendimentos como o Alphaville São Luís na área de expansão próxima às rodovias MA-201 e MA-202, geralmente destinados as classes média e classes médias altas.

\section{Mapa 04. RMGSL: densidades demográficas}

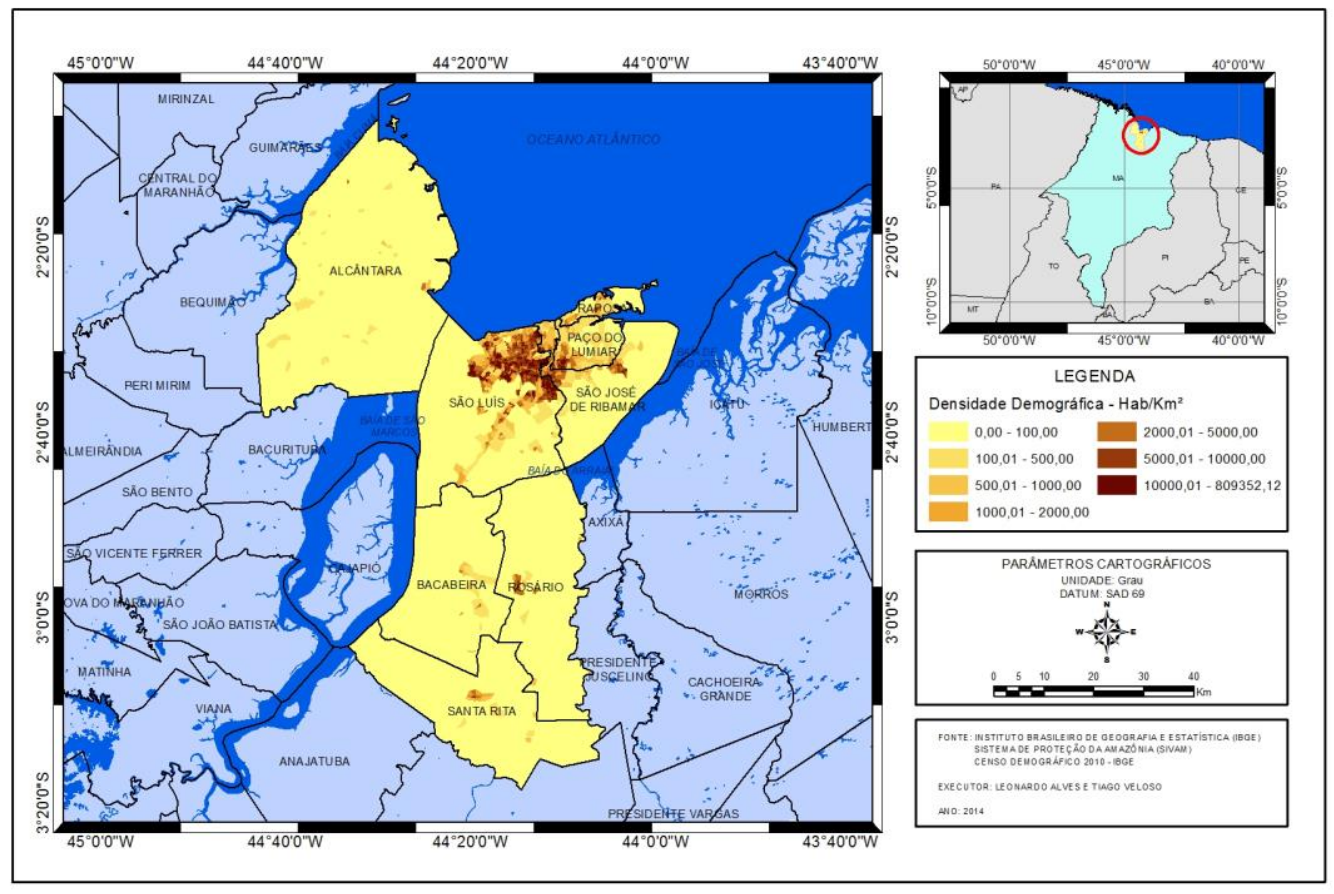


Em oposição à localização das classes de renda mais alta, as áreas residenciais populares estão distantes do centro, particularmente nos municípios que formam a periferia metropolitana distante, portanto, menos dotados de infraestrutura e serviços. Esse padrão de ocupação pode ser percebido no mapa 04, que apresenta as diferentes densidades demográficas da Região Metropolitana da Grande São Luís, e deixa mais claro o adensamento nos municípios próximos ao núcleo metropolitano e na direção de expansão da ocupação. Portanto, a estrutura metropolitana de São Luís mostra uma realidade segregada entre as áreas residenciais das classes de mais alta renda, que estão localizadas ao redor do núcleo urbanometropolitano. Há uma tendência de expansão da malha metropolitana em direção aos municípios de São José do Ribamar, Raposa e Paço do Lumiar às margens das rodovias MA201 e MA-202, que dão acesso a esses Municípios.

\section{CONSIDERAÇÕES FINAIS}

Tomada como referência de estudo, a problemática que se apresentou ao longo deste texto apresenta uma análise da formação de espaços metropolitanos, compreendido esse processo a partir do sentido da metropolização do espaço regional como consequência mais atualizada da integração nacional e da inserção internacional da região à economia-mundo.

Ainda assim, o fato de que o movimento de integração da região em uma dinâmica de fronteira, orientada pelo Estado brasileiro, não faz com que simplesmente as estruturas urbanas das metrópoles apresentem um padrão comum a todas elas. Ao contrário, as particularidades metropolitanas assumem forma quando consideramos os distintos modos com a qual cada uma dessas referências teve o processo de metropolização induzido.

Por se tratar de um processo complexo em uma região recentemente integrada a economia e o território nacional, apresenta padrões distintos frente à realidade da urbanização, daí podemos afirmar, então, que a metropolização do espaço seria a repercussão mais intensa da urbanização do território, como já havia sido aludido por Santos (2005), entretanto, não necessariamente apresentando padrões homogêneos em escala nacional.

Nesse sentido, o fenômeno da metropolização regional diz respeito, também, à maneira pela qual se apresenta esse processo pelo território nacional. Para Monte-Mór (2003) a ideia de uma urbanização extensiva como um processo de transformação socioespacial em que os fluxos e as lógicas de produção e reprodução de espacialidades diversas e distantes das 
grandes cidades se espelham cada vez mais nos processos urbanos que se verificam em pontos isolados do território.

A urbanização extensiva, portanto, carrega consigo as condições gerais de produção (LOJKINE, 1981) e a difusão do meio técnico-científico informacional (SANTOS, 2004) para determinadas porções do território interligadas por eixos viários (e mais recentemente, pelas tecnologias avançadas e praticamente onipresentes de telecomunicações) estruturadores deste processo (MAGALHÃES, 2008).

Em São Luís, o fenômeno da metropolização é decorrente da indução de duas variáveis que tem a ver com os projetos de integração e desenvolvimento regional e com a chegada das formas mais intensificadas da urbanização pelo território brasileiro. Assim, é a combinação da chegada de empreendimentos logísticos de grande porte com as frentes de trabalho advindas do interior da Amazônia oriental, que estimulam os elementos que possibilitaram a estruturação de um espaço metropolitano recente.

A concentração dos grandes objetos logísticos no interior da cidade de São Luís aponta para a concentração de capitais e população ainda na cidade. Mas o empobrecimento de boa parte da população e a valorização imobiliária induzem ao menos a uma tendência de conurbação com os municípios mais próximos.

Para entender a estruturação de um espaço metropolitano regional dessa magnitude na região, em um primeiro objetivo deste texto, demonstra-se como a partir de processos e dinâmicas pretéritas, advindas desde a formação territorial da região amazônica sob influência da colonização, o oeste maranhense apresenta aspectos de contiguidade com a formação socioespacial amazônica. Tais aspectos são reforçados em momentos significativos da história regional, tais como a formação de um estado comum, em um primeiro momento o Estado do Maranhão e Grão-Pará, substituído pelo Estado do Grão-Pará e Maranhão no período das reformas pombalinas, mas sem perder a noção de contiguidade regional.

Esses laços são também visualizados nos fluxos migratórios de maranhenses em direção ao estado do Pará e ao Amazonas no período da economia da borracha, já em fins do Império e início da República, trazendo uma contribuição à formação do mercado de trabalho e da mão-de-obra da região. Tais laços de certa forma induzem, já na segunda metade do século XX, a participação do Oeste maranhense a Amazônia como região de planejamento e desenvolvimento de atividades econômicas guiadas pelos grandes projetos de integração nacional. A partir de então intensificam-se os processos de urbanização regional e a metropolização derivada de tendências já realizadas no restante do território brasileiro. 
O quadro geral de análise da estrutura metropolitana em São Luís, portanto, oferece a compreensão desse aglomerado no contexto do processo de metropolização regional que se intensifica na Amazônia nas primeiras décadas do século XXI.

Como primeira característica, apontamos que a metropolização do espaço regional é intensificado pelos processos de integração á economia brasileira, especialmente via instalação de grandes empreendimentos econômico-espaciais na cidade de São Luís, intensificando um processo de metropolização que já estava colocado como tendência para o Brasil como um todo e para a Amazônia em particular. A execução do projeto de integração provocou mudança significativa no padrão espacial e territorial da Amazônia oriental, que, se antes era mobilizado pela economia agrário-extrativa dos vales do leste interior do Maranhão, agora se faz a partir da mobilização de capitais e populações em direção à São Luís e aos grandes projetos econômicos e logísticos desenvolvidos na metrópole, intensificando a metropolização do espaço como processo e tendo relação estreita com as dinâmicas regionais.

O caso de São Luís apresenta dois processos que corroboram para a sua dinâmica metropolitana. Um que se manifesta do interior de sua sub-região em direção à metrópole, em razão de sua articulação com o grande projeto Carajás e a sua conexão através da ferrovia, que estabelece um binômio mina-metrópole (VICENTINI, 2004). Outro que se manifesta internamente à metrópole, marcado pela instalação de complexo industrial de alumina associado à estruturação de portos exportadores.

Dessa forma, em São Luís, a concentração dos objetos logísticos no interior da cidade repercutiu em um movimento de concentração de capitais e de população no espaço urbano, provocando, gradativamente a intensificação da urbanização do território e da sociedade regional. A resultante desse processo é a metropolização do espaço no entorno imediato de São Luís, condicionando um processo que apresenta características de segregação social, tendo em vista que o empobrecimento de boa parte da população e a valorização imobiliária das áreas centrais da cidade induzem a uma conurbação periférica com os municípios próximos, que constituem o espaço metropolitano de São Luís.

Nesse caso, identificamos que o padrão intraurbano da metrópole é influenciado por essas dinâmicas regionais, que interagem com capitais internos às cidades, portanto, pode-se afirmar que, no caso amazônico, ou mais particularmente no caso de São Luís, a dinâmica regional está presente no âmbito da organização desses espaços. Esse processo provoca também, respostas dos agentes institucionais, o que em São Luís, redundou na criação de uma 
região metropolitana relativamente recente, com vista ao planejamento dessa nova forma do urbano na Amazônia.

\section{REFERÊNCIAS}

BECKER, B. Amazônia. São Paulo: Ática, 1990.

Revisão das políticas de ocupação da Amazônia: é possível identificar modelos para projetar cenários? In: Modelos e cenários para a Amazônia: o papel da ciência. Parcerias Estratégicas, n. 12, 2001, pp. 135-159. 2001.

BENCHIMOL, S. Amazônia Legal na década de 70/80: Expansão e concentração demográfica. Manaus, CEDEAM/UA, 1991.

BROWDER, J. O; GODFREY, B. J. Cidades da Floresta: Urbanização, desenvolvimento e globalização na Amazônia brasileira. Manaus: EDUA, 2006.

BURNETT, F. L. Urbanização e desenvolvimento sustentável: a sustentabilidade dos tipos de urbanização em São Luís do Maranhão. São Luís: EDUEMA, 2008.

CORDEIRO, E. C. Institucionalização metropolitana como triunfo e estratégia política: uma compreensão a partir da Região Metropolitana da Grande São Luís. In: ENCONTRO DA ASSOCIAÇÃO DE PÓS-GRADUAÇÃO EM PLANEJAMENTO URBANO E REGIONAL, 10, 2013, Recife. Anais...Recife: 2013.

CORDEIRO, E. C. Institucionalização metropolitana sobre espaços não-metropolitanos: o caso da Região metropolitana da Grande São Luís. 137f. Dissertação (Mestrado). Universidade Estadual do Maranhão. São Luís, 2014.

CORDEIRO, E. C.; DINIZ, J. S. Região Metropolitana da Grande São Luís: sua(s) constituição(ões) e atuais dilemas para gestão intergovernamental. Ciências Humanas em Revista, São Luís, v. 7, n. 2. 2009.

CORRÊA, R. L. A periodização da rede urbana da Amazônia. Revista Brasileira de Geografia, Rio de Janeiro, v. 4, n.3, p. 39-68, jul./set. 1987.

FERREIRA, A. J. A. O Estado e as políticas do urbano em São Luís. 1999. 223f. Dissertação (Mestrado) - Faculdade de Filosofia, Letras e Ciências Humanas, Universidade de São Paulo, São Paulo, 1999.

IBGE (Instituto Brasileiro e Geografia e Estatística) Sistema IBGE de Recuperação de Dados. Informações dos Censos demográficos brasileiros: 1950, 1960, 1970, 1980, 1991, 2000, 2010. Brasília: IBGE, 2010.

LOJKINE, J. O Estado capitalista e a questão urbana. São Paulo: Martins Fontes, 1981.

LUZ, J. S. Lutas por moradia e expansão do espaço urbano na cidade de São Luís. 2004. 132f. Dissertação (Mestrado) - Universidade Federal do Maranhão, São Luís, 2004.

MACHADO, L. O. Urbanização e mercado de trabalho na Amazônia brasileira. Cadernos IPPUR, v. XIII, n. 1, p. 109-138, jan./jul.1999.

MARANHÃO. Produto interno bruto do Maranhão: 2006 - 2010. São Luís: IMESC, 2012. MARANHÃO. Estudos sobre a economia maranhense. São Luís: IMESC, 2013.

MAGALHÃES, F. N. Da metrópole à cidade-região: na direção de um novo arranjo espacial metropolitano? Revista de Estudos Urbanos e Regionais, Rio de Janeiro, v. 10, n. 2, nov. 2008.

MONTE-MÓR, R. L. Outras Fronteiras: novas especialidades na urbanização brasileira. In: CASTRIOTA, L. B. (Org.). Urbanização brasileira: redescobertas. Belo Horizonte: Editora C/ Arte, 2003. 
PORTELA, R. S. Políticas habitacionais em metrópoles amazônicas: Belém e São Luís na perspectiva comparativa. 2011. 328 f. Tese (Doutorado) - Universidade Federal do Pará, 2011.

SANTOS, M. A Natureza do espaço: técnica e tempo, razão e emoção. São Paulo: Edusp, 2004.

A urbanização brasileira. São Paulo: Edusp, 2005.

SANTOS, F. V. O governo das conquistas do Norte: trajetórias administrativas no Estado do Grão-Pará e Maranhão (1751 - 1780). Tese (Doutorado). Faculdade de Filosofia, Letras e Ciências Humanas, Universidade de São Paulo, São Paulo, 2008.

TRINDADE JR., S. C. C. Grandes projetos, urbanização do território e metropolização na Amazônia. Revista Terra Livre, São Paulo, v. 26, p. 177-194, 2006.

VELOSO, T. Metrópole e Região na Amazônia: trajetórias do planejamento e da gestão metropolitana em Belém, Manaus e São Luís. 2015. Tese (Doutorado) - Universidade Federal do Pará, 2015.

VICENTINI, Y. Cidade e história na Amazônia. Curitiba: Editora da UFPR, 2004. 